www.jmscr.igmpublication.org

Impact Factor 5.84

Index Copernicus Value: 71.58

ISSN (e)-2347-176x ISSN (p) 2455-0450

crossref DOI: _https://dx.doi.org/10.18535/jmscr/v5i11.83

\author{
Journal Of Medical Science And Clinical Research \\ IGM Publication \\ An Official Publication of IGM Publication
}

\title{
A Comparative Study of the Effect of Fentanyl 25 MCG with Bupivacaine 0.5\% Verses Buprenorphine 60 MCG with Bupivacaine 0.5\% in Spinal Anaesthesia for Elective Caesarean Section
}

\author{
Authors \\ Dr S. Sittaramane ${ }^{1}$, Prof. Dr M. Dhakshinamoorthy ${ }^{2}$ \\ ${ }^{* 1}$ Post Graduate Student, Dept of Anaesthesia, Rajah Muthiah Medical College and Hospital, \\ Chidambaram, Tamil Nadu, India \\ ${ }^{2}$ Professor and Head, Dept of Anaesthesia, Rajah Muthiah Medical College and Hospital, Chidambaram, \\ Tamil Nadu, India
}

\begin{abstract}
Introduction: Pregnancy is accompanied by physiologic changes in multiple organ systems that may influence maternal responses to anaesthesia and the choice of anaesthetic techniques. The rate of caesarean sections is on the rise. Caesarean section in a conscious patient is a challenging test of regional anaesthesia. Spinal anaesthesia is perhaps the most efficient approach to this challenge. In modern scientific era, there has been a curiosity in using opioid analgesic adjuvants to subarachnoid local anaesthetics. Arrival of a new synthetic lipophilic opioid, fentanyl, has revolutionized its use in the past three decades. Fentanyl has a shorter duration of action and fast onset as compared to pethidine and morphine. Buprenorphine is a long acting, highly lipophilic opioid. It has proved to be a promising analgesic by intra thecal route ${ }^{1,2}$. Buprenorphine is twenty five times more potent than morphine. In this study, an effort is made to compare the perioperative and postoperative analgesic efficiency of these two lipophilic opioid drugs along with bupivacaine in caesarean section.

Aim: To evaluate the efficacy of the combination of intrathecal fentanyl $25 \mathrm{mcg}$ and $7.5 \mathrm{mg}$ of $0.5 \%$ hyperbaric bupivacaine in comparison with buprenorphine $60 \mathrm{mcg}$ and $7.5 \mathrm{mg}$ of $0.5 \%$ hyperbaric bupivacaine used for lower segment caesarean section

Materials and Methods: A total of 50 patients who underwent elective caesarean section were taken up for the study. Patients were randomised into two groups each. In group A, patients recieved $1.5 \mathrm{ml}$ of $0.5 \%$ hyperbaric bupivacaine $(7.5 \mathrm{mg})$ with $0.5 \mathrm{ml}$ of fentanyl $(25 \mathrm{mcg})$ and in group B, patients received $1.5 \mathrm{ml}$ of $0.5 \%$ hyperbaric bupivacaine $(7.5 \mathrm{mg})$ with $0.2 \mathrm{ml}$ of buprenorphine $(60 \mathrm{mcg})$ and $0.3 \mathrm{ml}$ of normal saline. The final volume of the injected solution is $2 \mathrm{ml}$ on both groups.

Results: In the current study, onset of analgesia was significantly earlier due to the addition of buprenorphine. This may be attributed to high lipid solubility and highest affinity for opiate receptors of buprenorphine. Both the groups had the same mean time to achieve motor blockade. Both groups maintained hemodynamic stability which was statistically insignificant. The mean duration of effective analgesia was 200.32 minutes (3.33 hours) in Group A and 491.28 minutes ( 8.1 hours) in group B which was highly significant statistically $(p<0.01)$.

Conclusion: We observed that anaesthesia was superior when buprenorphine is mixed with bupivacaine (0.5\%) as compared to bupivacaine with fentanyl. Addition of buprenorphine to bupivacaine $0.5 \%$ augments the sensory blockade of local anaesthetics without affecting the sympathetic activity. Thus it is concluded that intrathecal buprenorphine is suitable drug for post operative analgesia for caesarean section .

Keywords: Caesarean section, Spinal anaesthesia, bupivacaine, fentanyl, buprenorphine, post operative analgesia.
\end{abstract}




\section{Introduction}

Pregnancy is accompanied by physiologic changes in multiple organ systems that may influence maternal responses to anaesthesia and the choice of anaesthetic techniques. According to a recent analysis of national health data, the rates of average caesarean sections done in our country has gone up from five percent to 18 percent over the last few decades.

Caesarean section in a conscious patient is a challenging analysis of regional anaesthesia. The most efficient approach to this challenge is spinal anaesthesia. The advantages are

1. Small needle

2. Profound anaesthesia,

3. Minimal amount of drug and

4. Excellent operating conditions, that can be readily provided for the major surgeries like LSCS.

Hypotension following spinal anaesthesia is the most clinically significant aspect, that can occur rapidly and may have a significant aspect on the neonatal outcome. In the last few decades, there has been a curiosity in using opioid analgesic adjuvants to subarachnoid local anaesthetics to decrease the local anaesthetic dose, hence reducing the occurrence and degree of hypotension, at the same time without compromising intra operative analgesia and to enable faster recovery also providing efficient post operative analgesia.

The discovery of opioid receptors in the spinal cord and intrathecal opioid administration has opened a new horizon in pain management during perioperative period, and it has gained significance in the past three decades.

Arrival of a new synthetic lipophilic opioid, fentanyl, has revolutionized its use in the past three decades .Fentanyl has a shorter duration of action and fast onset as compared to pethidine and morphine. It acts as an agonist to mu receptors. Fentanyl is more specific, shorter acting and about hundred times more potent than morphine. It is less hydrophilic and has little rostral spread which causes lesser respiratory depression when compared with morphine.

Buprenorphine is an opioid with high lipophilic property and longer duration of action. It has proved to be a favourable analgesic by intrathecal route $^{1,2}$. Buprenorphine is twenty five times more potent than morphine. Buprenorphine is an agonist - antagonist with lipid solubility about five times greater than that of morphine and has a low level of physical dependence ${ }^{3}$. Buprenorphine is associated with lower incidence of respiratory depression because there is no rostral spread. But it has been associated with urinary retention ${ }^{4}$.

In the study, an effort is made to compare the perioperative and postoperative analgesic efficiency of these two lipophilic opioid drugs along with bupivacaine in caesarean section.

\section{Aim}

In this context, the present study was undertaken to evaluate the efficacy of the combination of intrathecal fentanyl $25 \mathrm{mcg}$ and $7.5 \mathrm{mg}$ of $0.5 \%$ hyperbaric bupivacaine in comparison with buprenorphine $60 \mathrm{mcg}$ and $7.5 \mathrm{mg}$ of $0.5 \%$ hyperbaric bupivacaine used for lower segment caesarean section with respect to

1. Time of onset of analgesia and motor blockade

2. Duration of sensory and motor block

3. Quality of intra operative anaesthesia

4. Incidence of hypotension

5. Ephedrine requirement to combat hypotension

6. Foetal outcome

7. Duration of post operative analgesia

\section{Materials and Methods}

After getting proper concurrence from ethics committee, The present study was conducted in Rajah Muthiah medical college and hospital, Annamalai university. A total of 50 patients who underwent elective caesarean section were selected for the study. The age of the patients ranged from 20-37 years weighing 40-65 kg and height ranging from 140-167 cms. All patients were thoroughly examined pre-operatively. Patients belonging to ASA grade I and grade II 
were alone taken up for the study. Initially, patients were reassured and counselled to gain confidence. The procedure was explained and an Informed consent was obtained.

Inj. Ranitidine 50mg was given intravenously as premedication 45 minutes before surgery and patients were randomised into two groups each.

GROUP A: Patients received $1.5 \mathrm{ml}$ of $0.5 \%$ hyperbaric bupivacaine $(7.5 \mathrm{mg})$ with $0.5 \mathrm{ml}$ of fentanyl (25 mcg)

GROUP B: Patients received $1.5 \mathrm{ml}$ of $0.5 \%$ hyperbaric bupivacaine $(7.5 \mathrm{mg}$ ) with $0.2 \mathrm{ml}$ of buprenorphine $(60 \mathrm{mcg})$ and $0.3 \mathrm{ml}$ of normal saline.

The final volume of the injected solution is $2 \mathrm{ml}$ on both groups.

In preoperative assessment clinic, baseline investigations like haemoglobin, urine analysis for albumin and sugar, blood sugar, urea, creatinine and ECG were checked. Vital parameters like pulse rate, blood pressure respiratory rate were recorded. Thorough examinations of all the systems and airway assessment was done. The patients were educated about Visual analogue scale (VAS) and its interpretations.

In the operating room, appropriate equipment for airway management and emergency drugs were kept ready. Patients were shifted to the operating room. The horizontal position of the operating table was checked and the patient was placed on it. The noninvasive blood pressure monitor, pulse oximeter and electro cardiogram leads were connected to the patient. In the anaesthesia chart, proper recording of preoperative baseline systolic and diastolic blood pressure, pulse rate, respiratory rate and oxygen saturation was documented. 18G intravenous cannula was secured to the patients and preloading was done with $1000 \mathrm{ml}$ of Ringers lactate. The patient was placed in left lateral position. The skin over the back were cleaned with swabs and antiseptic solution and draped with sterile towel. The L3 L4 interspaces was identified and 25G Quincke Babcock spinal needle was introduced in this space through midline approach. After confirming free flow of CSF, the prepared solution was injected. The patients were made to lie supine immediately after injection and left lateral tilt was provided by wedge under right buttock.

The time of onset and duration of sensory block, motor block were noted. The grading of motor block was done according to modified bromage scale.

\section{Modified Bromage scale}

0 - No block. Able to raise extended leg against gravity

1 - Unable to raise extended leg, just able to flex knees

2 - Unable to flex knees, but able to flex ankle

3 - Total block. Inability to flex ankle / move leg.

The systolic and diastolic blood pressure, pulse rate, respiratory rate and oxygen saturation were noted every minute for the first 10 minutes and thereafter every 5 minutes until the immediate post operative period.

Side effects such as nausea, vomiting, hypotension, respiratory depression, pruritus and allergic reaction were looked and were reported, if any.

Time interval between subarachnoid block and the time to reach VAS $\geq 4$ is defines as the "duration of effective analgesia".

In the post anaesthesia care unit, pain assessment using VAS was done every 15 minutes till VAS score $\geq 4$ was reached. The APGAR scores of the newborn were recorded at 1 minute and 5 minute intervals after delivery of the baby.

\section{Observations and Results}

A total of 50 patients participated in the study and the statistical data were analysed. The average age in both groups were similar. The mean weight and height of the patients were comparable in both groups and they were statistically insignificant.

\section{Sensory block}

The mean time of onset of sensory block at $\mathrm{T}_{10}$ was138.6 \pm 22.61 seconds in Group A with a range of $105-180$ seconds and $112 \pm 23.4$ seconds 
in Group B with a range of 80-154 seconds. This was statistically significant which was confirmed by unpaired Student's test $(p<0.05)$ as shown in the bar diagram.

\section{Maximum level of sensory block}

The range of maximal level of sensory block was $\mathrm{T}_{4-} \mathrm{T}_{7}$ in Group A and in Group B, it was between $\mathrm{T}_{4}-\mathrm{T}_{8}$.

\begin{tabular}{|l|c|c|}
\hline \multirow{2}{*}{ Level } & \multicolumn{2}{|c|}{ Number of patients } \\
\cline { 2 - 3 } & Group A & Group B \\
\hline $\mathrm{T}_{4}$ & 6 & 3 \\
\hline $\mathrm{T}_{5}$ & 13 & 3 \\
\hline $\mathrm{T}_{6}$ & 5 & 15 \\
\hline $\mathrm{T}_{7}$ & 1 & 3 \\
\hline $\mathrm{T}_{8}$ & 0 & 1 \\
\hline
\end{tabular}

\section{Time to regression to $\mathrm{L}_{1}$}

The mean time to regression of sensory blockade to $L_{1}$ was $200.32 \pm 9.1$ minutes, with a range of $173-234$ minutes in Group A .In Group B, it was $491.28 \pm 153.97$ minutes, with a range of $420-$ 540 minutes. This was statistically significant $(\mathrm{p}<$ $0.01)$.

\section{Maximum level of sensory block}

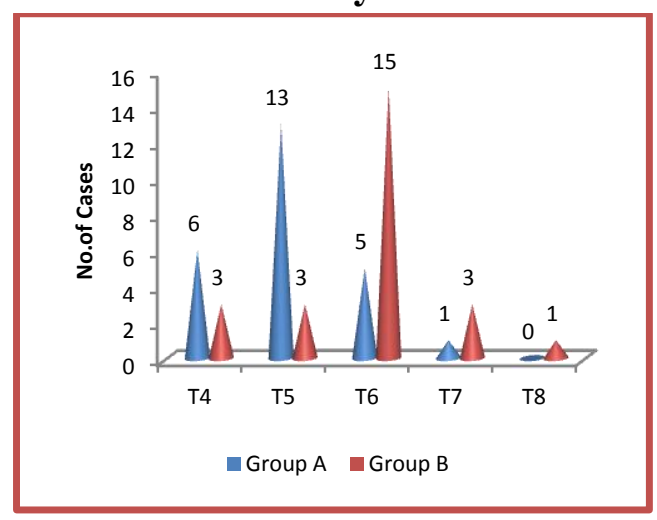

\section{Motor block}

\section{Onset of Grade I motor block}

The time taken to achieve Grade I motor block was $159 \pm 20.31$ seconds in Group A with a range of $120-195$ seconds. In Group B, it was $160.8 \pm$ 22.3 seconds with a range of $135-210$ seconds. This was found to be statistically insignificant ( $p$ $>0.1$ ).

\section{Maximum degree of motor block}

The maximum degree of motor block ranged between grade 3 and grade 2 in both the groups.
The distribution of patients in each grade is shown in the table.

\begin{tabular}{|l|c|c|}
\hline \multirow{2}{*}{$\begin{array}{l}\text { Degree of Motor } \\
\text { Block }\end{array}$} & \multicolumn{2}{|c|}{ Number of Patients } \\
\cline { 2 - 3 } & Group A & Group B \\
\hline GR0 & 0 & 0 \\
\hline GR1 & 0 & 0 \\
\hline GR2 & 3 & 7 \\
\hline GR3 & 22 & 18 \\
\hline
\end{tabular}

\section{Duration of motor block}

The mean duration of motor block was $70.8 \pm$ 11.06 minutes in Group A with range of $60-90$ minutes. In Group B, it was $69.54 \pm 20.23$ minutes with a range of $60-90$ minutes. This was found to be statistically insignificant ( $p>0.1$ ).

\section{Degree of motor block}

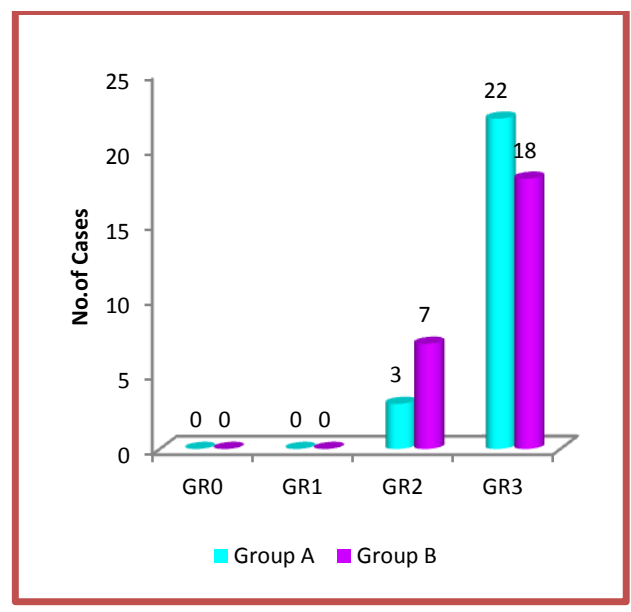

Mean Arterial Pressure variation in study groups

\begin{tabular}{|c|c|c|c|c|}
\hline \multirow{2}{*}{ MAP } & \multicolumn{2}{|c|}{ Group A } & \multicolumn{2}{|c|}{ Group B } \\
\hline & Mean & SD & Mean & SD \\
\hline Initial MAP & 89.8 & 6.6 & 90.5 & 7.5 \\
\hline Minimum MAP & 83.2 & 7.5 & 83.2 & 6.7 \\
\hline Average MAP & 89.5 & 5.5 & 89.8 & 4.9 \\
\hline Fall in MAP & 6.5 & 8.1 & 7.3 & 66.4 \\
\hline$\%$ fall in MAP & 7.2 & 7.8 & 7.8 & 6.8 \\
\hline
\end{tabular}

The fall in Mean Arterial Pressure was insignificant in all 2 groups. Thus, addition of low dose fentanyl and buprenorphine gives an added advantage of hemodynamic stability when compared to plain bupivacaine alone. 


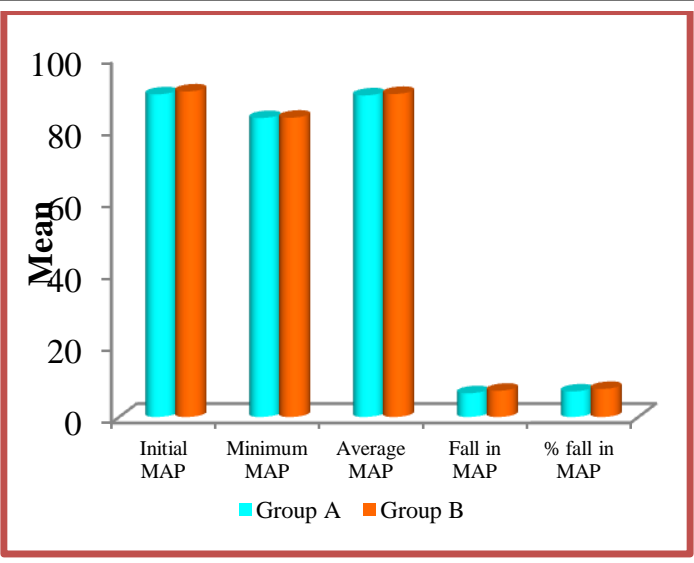

Respiratory rate and $\mathrm{SpO} 2$ among the study groups

\begin{tabular}{|l|c|c|c|c|}
\hline \multirow{2}{*}{} & \multicolumn{2}{|c|}{$\begin{array}{c}\text { Respiratory } \\
\text { rate }\end{array}$} & \multicolumn{2}{c|}{ Spo } \\
\cline { 2 - 5 } & $\begin{array}{c}\text { Group } \\
\text { A }\end{array}$ & $\begin{array}{c}\text { Group } \\
\text { B }\end{array}$ & $\begin{array}{c}\text { Group } \\
\text { A }\end{array}$ & $\begin{array}{c}\text { Group } \\
\text { B }\end{array}$ \\
\hline Mean & 14.8 & 14.9 & 99.8 & 99.6 \\
\hline SD & 1.1 & 1.2 & 0.54 & 0.69 \\
\hline $\begin{array}{l}\text { 'p' for 2 } \\
\text { groups }\end{array}$ & \multicolumn{2}{|c|}{$\begin{array}{c}0.5526, \text { not } \\
\text { significant }\end{array}$} & \multicolumn{2}{c|}{$\begin{array}{c}\text { 0.7826, not } \\
\text { significant }\end{array}$} \\
\hline
\end{tabular}

There was no significant difference in the two groups, with respect to Respiratory rate and $\mathrm{SpO} 2$. Almost both the groups are stable in this aspect. There are no reports of desaturation and respiratory depression.

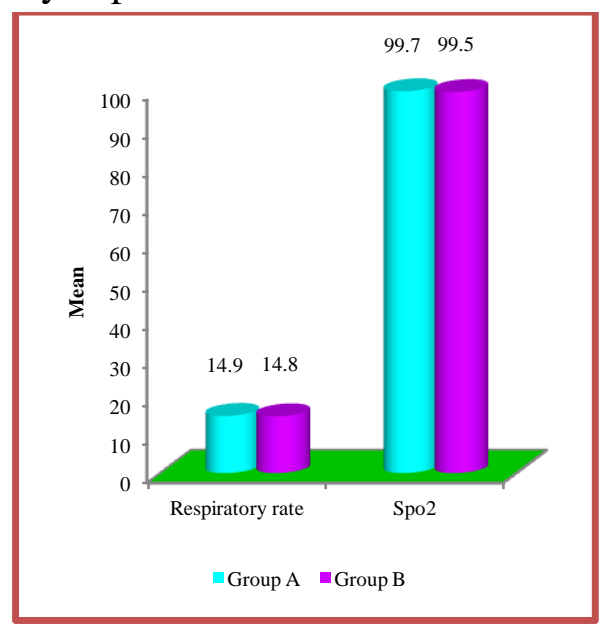

\section{Duration of effective analgesia}

The mean duration of effective analgesia was $200.32 \pm 9.1$ minutes (3.33 hours) with a range of 173 - 234 minutes in Group A, but in Group B, it was $491.28 \pm 153.97$ minutes (8.1 hours) with a range of $420-540$ minutes. This was statistically highly significant. $(p<0.01)$

\section{Quality of surgical anaesthesia}

In this study, the quality of surgical anaesthesia was graded as 'excellent' in all, but 3 patients in Group A complained of discomfort intraoperatively and required $10 \mu \mathrm{gm}$ fentanyl intravenously.

\section{Incidence of hypotension}

In Group A, 12 patients had hypotension whereas in Group B, only 7 patients had hypotension. The incidence is $48 \%$ with Group A against $28 \%$ in Group B. This was tested to be statistically significant. $\quad(p<0.001)$

\section{Mean ephedrine requirement}

The mean ephedrine required to counter hypotension was $12 \mathrm{mg}$ in Group A, whereas it was $3.12 \mathrm{mg}$ in Group B.

Duration of post operative analgesia (in minutes)

\begin{tabular}{|l|c|c|}
\hline $\begin{array}{l}\text { Post operative } \\
\text { analgesia (mins) }\end{array}$ & Group A & Group B \\
\hline Mean (mins) & 200.32 & 491.28 \\
\hline SD & 9.1 & 153.97 \\
\hline 'p' value for 2 groups & \multicolumn{2}{|c|}{0.0001 , significant } \\
\hline
\end{tabular}

The post operative period is, till the patient demands systemic analgesic (i.e., VAS score $\geq 4$ ) from the initiation of subarachnoid blockade. The mean duration of effective analgesia was $200.32 \pm$ 9.1 minutes (3.33 hours) with a range of 173 234 minutes in Group A, but in Group B, it was $491.28 \pm 153.97$ minutes (8.1 hours) with a range of $420-540$ minutes. This was statistically highly significant. $\quad(\mathrm{p}<0.01)$

Side effects

\begin{tabular}{|l|l|l|}
\hline \multirow{2}{*}{ Side Effects } & \multicolumn{2}{|l|}{ Number of patients } \\
\cline { 2 - 3 } & Group A & Group B \\
\hline Pruritus & 4 & 0 \\
\hline Nausea & 2 & 6 \\
\hline sedation & 7 & 17 \\
\hline
\end{tabular}

The incidence of pruritus was $16 \%$ in Group A (4 patients) whereas it was nil with Group A. Pruritus in Group A was mild and settled with reassurance.

6 patients complained of nausea in Group B and 2 in Group A. This was attributed to the addition of 
opioids to bupivacaine. Bradycardia and respiratory depression did not occur in any of the patients involved in the study.

In our study, most of the patients were catheterized before shifting to operation theatre, hence urinary retention could not be assessed and compared.

Sedation of grade I was seen with 17 patients in Group B.

\section{Assessment of the fetus}

All the babies showed 1 minute APGAR of 8 and above and 5 minute APGAR of 9 and above in both the groups. The difference was statistically insignificant.

\section{Discussion}

"Pain is a more terrible lord of mankind than death itself". Pain is a complicated subjective experience, which is challenging to measure in a reproducible way ${ }^{5}$. Operative pain is more extreme after surgery which thereafter gradually tapers over the next 24 hours $^{6}$. Existance of pain has been a led to the discovery of both newer drugs and procedures of pain relief.

The principal aim of this study was to analyze the efficacy of the combination of fentanyl with bupivacaine verses buprenorphine with bupivacaine in spinal anesthesia for elective caesarean section regarding incidence of hypotension and mean ephedrine requirements apart from other usual parameters and to compare the duration of postoperative analgesia.

Intrathecal opioids were first clinically used by Wang et $\mathrm{al}^{7}$. Postural hypotension and exaggerated sympathetic blockade is absent with use of opioids, hence parturient are allowed to ambulate early and mother can breastfeed child effectively, thereby improving interaction between mother and child ${ }^{8}$. Risk of thromboembolic disease is increased during pregnancy. Excellent pain relief is provided postoperatively by intrathecal buprenorphine, hence it enhances early ambulation, thereby decreasing chances of thromboembolic phenomenon.
Without affecting motor block, buprenorphine increases duration of sensory block and gives preferable hemodynamic stability ${ }^{9}$. In the present study, the buprenorphine group had significant early onset of analgesia. This is by virtue of high lipid solubility and highest affinity for opiate receptors of buprenorphine ${ }^{10,11}$.

The findings in our study also correlates with the study done by Singh H, Yang J, Thornton K and Giesecke $^{12} \mathrm{AH}$ who concluded that addition of intrathecal fentanyl $25 \mu \mathrm{g}$ to hyperbaric bupivacaine did not hasten the onset of sensory block.

The duration of motor block was not prolonged much by the addition of fentanyl/buprenorphine to $0.5 \%$ hyperbaric bupivacaine intrathecally. With increase in dose of bupivacaine, the duration of motor block was increased. Hence, by adding opioid adjuants, we reduce the dose of bupivacaine thereby reducing the undesiarable long duration of motor blockade which causes delay in ambulation in post operative period.

The mean duration of effective analgesia was 200.32 minutes (3.33 hours) in Group A and 491.28 minutes (8.1 hours) in group B which was highly significant statistically. In our study the duration of analgesia was increased due to addition of buprenorphine, the same theory was analysed by capogna etal ${ }^{13}$, who concluded that the duration of analgesia is dose dependent. Longer duration of action and analgesic efficacy of intrathecal buprenorphine can be explained by its high affinity for spinal receptors. Smaller doses of buprenorphine produce a high concentration of the drug at spinal receptors. Higher lipid solubility of buprenorphine favours its diffusion to spinal cord. The diffusion from the spinal cord in to the bloodstream is slow and does not approach the bulbar centres with bulk of CSF. Hence high lipid solubility, strong opiate receptor binding and intense and prolonged activity was responsible for its longer duration of action ${ }^{14}$.

In our study, 3 patients in group A complained of discomfort intraoperatively and required supplementation with intravenous fentanyl $10 \mu \mathrm{g}$. 
The quality of surgical anaesthesia was excellent in all other patients.

In our study, the incidence of hypotension was $48 \%$ in group A and $28 \%$ in group B. This was statistically significant. Our study confirmed the fact that the decrease in sympathetic efferent activity after spinal anesthesia with bupivacaine was dose related and that intrathecal opoids caused neither by itself nor in combination with bupivacaine, any further depression of efferent sympathetic activity. This correlated with the study of Ben David et al (1984) ${ }^{15}$.

Incidence of nausea, vomiting, pruritus were present in both the groups which may be contributed due to addition of opioids, yet, all the side effects were mild and mostly settled with reassurance. None of the patients developed respiratory depression or bradycardia.

With use of opioids, the incidence of Postural hypotension and exaggerated sympathetic blockade is absent. It allows parturient to ambulate early and mother can breastfeed child effectively thereby improving interaction between mother and child ${ }^{16}$. A good pain relief is provided in postoperative period by intrathecal buprenorphine, it improves mobility thereby reducing chances of thromboembolic phenomenon which is one of the risks associated with pregnancy and in postpartum period.

Intrathecal fentanyl and buprenorphine did not adversely affect the neonatal outcome.

\section{Conclusion}

In this comparative study, an effort was made to study the analgesic efficacy of fentanyl and buprenorphine with $0.5 \%$ bupivacaine intrathecally for elective caesarean section.

1) There was no significant hemodynamic changes in either of the groups.

2) Anaesthesia was superior when buprenorphine is mixed with bupivacaine $(0.5 \%)$ as compared to bupivacaine with fentanyl.

3) Addition of buprenorphine to bupivacaine $0.5 \%$ enhances the sensory blockade of local anaesthetics without

affecting

the sympathetic activity.

Thus it is concluded that intrathecal buprenorphine is suitable drug for post operative analgesia for caesarean section .

\section{References}

1. Celleno D, Capogna G. Spinal buprenorphine for postoperative analgesia after caesarean section. Acta anaesthesiol Scand 1989;33:236-8

2. Miwa Y, Yonemura E, Fukushima K, Epidurally administered buprenorphine in the preoperative period. Can J Anaesth 1996;43:907-13

3. Lalla RK. Low dose intrathecal buprenorphine for postoperative analgesia. Indian J Anaesth 1997;41:38-9

4. Bromage PR. The price of intraspinal narcotic analgesia: Basic constraints (editorial) Anaesth Analg. 1981 july ; 60(7) : 461-463

5. R.G. Wheatly, S.A.Schug, D.Watson. Safety and efficacy of postoperative analgesia. Br. J Anaesth 2001 Feb; 87(5) : 47-61.

6. Parkhouse, J.Lambrechts, R.w. Simpson. Incidence of postoperative pain. $\mathrm{Br} \mathrm{J}$ Anaesth. 1961 Apr; 33(4): 576-581.

7. Wang JK, Nauss LA, Thomas JK. Pain relief by intrathecally applied morphine in man. Anaesthesiology 1979; 50: 149-51.

8. Jeff Gasden, Stuart Hart and Alan C. Sandos. Post - cesarean delivery analgesia. Anaesth Analg 2005; 101: 62-69.

9. Atweth SF, Kuhar MJ. Autoradiographic localization of receptors in rat brain, spinal cord and lower medulla. Brain Research 1977; 124: 53-67.

10. Dikenson AH. Spinal cord pharmacology of pain. British Journal of Anaesthesia 1995; 75: 193.

11. Chang HM, Berde CB, Holz GG et al. sufentanil, morphine metenkephalin and $\mathrm{K}$ agonist (U-50, 488H) inhibit substance $\mathrm{P}$ 
release from primary sensory neurons: A model for presynaptic spinal opioid actions. Anaesthesiology 1989; 70:672

12. Singh H, Yang J, Thornton K, Giesecke AH. Intrathecal fentanyl prolongs sensory bupivacaine spinal block. Canadian Journal of Anesthesia 1995; 42(11):98791.

13. Singh H, Yang J, Thornton K, Giesecke $\mathrm{AH}$. Intrathecal fentanyl prolongs sensory bupivacaine spinal block. Canadian Journal of Anesthesia 1995; 42(11):98791.

14. Cahill J, Murphy D, O’Brain D, Mulhall J. Epidural buprenorphine for pain relief after major abdominal surgery. A controlled comparison with epidural morphine. Anaesthesia. 1983 Aug; 38(8): 760-764.

15. Ben-David B, Frankel R, Arzumonov T, Marchevsky Y, Volpin G. Minidose bupivacaine- fentanyl spinal for surgical repair of hip fracture in the aged. Anaesthesiology 2000; 92: 6-10

16. Wang JK, Nauss LA, Thomas JE. Pain relief by intrathecally applied morphine in man Anaesthesiology 1979; 50; 149-5. 